\title{
Influência do aporte térmico sobre a morfologia da austenita e na quantidade das fases em chapas soldadas de aço inoxidável duplex SAF2205
}

\author{
Influence of heat input on the morphology \\ of the austenite and the quantity of phases \\ in welded duplex stainless steel sheet SAF2205
}

\author{
Camila Soares Fonseca ${ }^{1}$, Ivete Peixoto Pinheiro ${ }^{1}$, \\ Sidney Nicodemos da Silva ${ }^{1}$
}

\begin{abstract}
${ }^{1}$ Programa de Pós Graduação em Engenharia de Materiais, Centro Federal de Educação Tecnológica de Minas Gerais, Av. Amazonas, 5253, 30421169, Belo Horizonte, MG

e-mail: camilasfonseca8@hotmail.com; ivetepinheiro@dppg.cefetmg.br; sidneynicodemos@yahoo.com.br
\end{abstract}

\section{RESUMO}

Os aços inoxidáveis duplex possuem uma microestrutura na qual a composição de ferrita e austenita, tem frações volumétricas próximas a 50 \%. Esses são utilizados na fabricação de diversos componentes e produtos, principalmente para aplicações na indústria petrolífera. Nestas aplicações muitas vezes são utilizados processos de soldagem. Para mitigar as alterações provocadas por esse processo nas propriedades do material é necessária uma escolha adequada dos parâmetros de soldagem. Neste contexto, o objetivo desse trabalho é avaliar o efeito do aporte térmico sobre a morfologia da austenita e na quantidade das fases, além de identificar qual condição de soldagem proporciona um equilíbrio das frações volumétricas de ferrita e austenita. Os materiais analisados são chapas de aço inoxidável duplex SAF2205, soldadas pelo processo de soldagem GMAW, na ESAB, variando-se o aporte térmico em 0,5, 1,0 e 1,5 kJ/mm. Após a soldagem, as chapas foram cortadas, preparadas para a análise metalográfica da morfologia de austenita formada e para a quantificação das fases. Os resultados mostraram a presença da austenita alotriomórfica de contorno de grão, a austenita de Widmanstätten e a austenita intragranular. Foi verificado que o aporte térmico que menos alterou o balanceamento das fases ferrita e austenita foi o de $1,5 \mathrm{~kJ} / \mathrm{mm}$, concluindo que se deve utilizá-lo quando o objetivo for manter a proporção volumétrica das fases no aço duplex SAF2205.

Palavras-chave: Aço inoxidável duplex, aporte térmico, microestrutura.

\section{ABSTRACT}

The duplex stainless steels have a microstructure wherein the composition of ferrite and austenite volume fraction is near 50\%. These are used in the manufacture of various components and products, mainly for applications in the oil industry. In these applications often welding processes are used. To mitigate this process changes due to the material properties a suitable choice of the welding parameters is needed. In this context, the aim of this study was to evaluate the effect of heat input on the morphology of the austenite and the amount of the phases, and identify which welding condition provides a balance of volume fractions of ferrite and austenite. The materials analyzed are stainless steel duplex sheet SAF2205, welded by GMAW welding process, the ESAB, varying the heat input in $0.5,1.0$ and $1.5 \mathrm{~kJ} / \mathrm{mm}$. After welding, the sheets were cut, prepared for metallographic examination of the morphology formed and austenite phases for quantification. The results showed the presence of alotriomórfica austenite grain boundaries, the austenite Widmanstätten and intragranular austenite. It was found that the heat input less altered the balance of ferrite and austenite phases was $1.5 \mathrm{~kJ} / \mathrm{mm}$, concluding that one should use it when the goal is to keep the volume ratio of the phases in duplex steel SAF2205.

Keywords: Duplex stainless steel, heat input, microstructure. 


\section{INTRODUÇÃO}

Os aços inoxidáveis duplex possuem um balanceamento entre as frações volumétricas próximo de 50\% para cada uma das fases, a fim de se maximizar as propriedades mecânicas que estão relacionadas com as características da fase austenítica e da fase ferrítica [1].

Os elevados valores de alongamento da austenita e o elevado limite de escoamento da ferrita nos aços inoxidáveis duplex possibilitam excelentes propriedades mecânicas para os mesmos. Esses aços possuem elevado limite de escoamento, aproximadamente duas vezes o valor dos aços inoxidáveis austeníticos. Quando utilizados em plataformas de exploração de petróleo, essa característica dos aços inoxidáveis duplex possibilita redução da parede de vasos e trocadores, consequentemente redução do peso e dos custos da fabricação da plataforma. A maior resistência à tração dos aços inoxidáveis duplex possibilita importantes reduções na seção deste, resultando em significativa economia de peso. Além disso, a elevada resistência à corrosão pode aumentar a vida útil dos equipamentos. De acordo com essas características, pode ser observado que os aços inoxidáveis duplex são bastante atrativos do ponto de vista econômico [2]].

Existem muitas aplicações para aços duplex que necessitam do processo de soldagem. Para mitigar as alterações que ocorrem devido a este processo nas propriedades mecânicas e na resistência à corrosão dos aços inoxidáveis duplex são necessários alguns cuidados durante o processo. Os processos de soldagem a arco convencional, praticamente todos, podem ser utilizados para a soldagem de aços inoxidáveis duplex. Já os processos de soldagem com uma fonte de energia de alta densidade, como o feixe de elétrons ou o laser, possuem utilização limitada. Nestes casos as altas velocidades de resfriamento da junta impossibilitam a precipitação da austenita [3] .Os ciclos térmicos que ocorrem durante a soldagem podem alterar o balanceamento das fases e com isso suas propriedades. Além disso, podem ocorrer precipitações de fases intermetálicas que são prejudiciais ao material. Dentre essas fases, pode-se destacar a fase Laves, a fase chi, carbonetos e a fase sigma, sendo esta última a mais verificada em aços inoxidáveis duplex. A fase sigma é indesejável por ser quebradiça, o que prejudica as propriedades mecânicas do aço, além de diminuir a resistência à corrosão do material devido à perda de cromo para a fase sigma [4]

Na soldagem de aços duplex um parâmetro fundamental de controle é o aporte térmico, uma vez que quanto maior, menor a taxa de resfriamento. Recomenda-se utilizar aporte térmico entre $0,5 \mathrm{~kJ} / \mathrm{mm}$ e 2,5 $\mathrm{kJ} / \mathrm{mm}$ para a soldagem de aços inoxidáveis duplex e entre $0,2 \mathrm{~kJ} / \mathrm{mm}$ e $1,5 \mathrm{~kJ} / \mathrm{mm}$ para os aços inoxidáveis super duplex (AISD) [ $\underline{5}$.

Diferentes fases intermetálicas podem surgir no aço inoxidável duplex de acordo com as temperaturas em que ele é submetido durante o processo de soldagem: fase Laves, a fase chi, carbonetos e a fase sigma. Dentre essas fases a que possui um volume mais considerável de precipitação em aços inoxidáveis duplex é a fase sigma. A fase sigma é indesejável por ser quebradiça, o que prejudica as propriedades mecânicas do aço, além de diminuir a resistência à corrosão do material devido à perda de cromo para a fase sigma. A precipitação da fase sigma ocorre principalmente pela decomposição da ferrita. A fase sigma é constituída de ferro, cromo e molibdênio, logo o aumento do teor desses elementos favorece a formação dessa fase. A influência da fase sigma na resistência a corrosão dos aços inoxidáveis duplex está relacionada ao empobrecimento de cromo na ferrita, pois precipitados intermetálicos ricos em cromo e molibdênio criam em regiões próximas a eles zonas empobrecidas nesses elementos [].

Quando é utilizado um aporte térmico elevado a velocidade de resfriamento da junta soldada é menor. O resultado é o favorecimento da precipitação de austenita, de fases intermetálicas e o crescimento do grão. Um aporte térmico baixo resulta em uma velocidade de resfriamento elevada e, consequentemente, a precipitação de austenita é dificultada e uma fração elevada de ferrita poderá ser formada. Neste caso, pode favorecer a precipitação de nitretos de cromo na ferrita. Tal fato se justifica uma vez que o nitrogênio não tem tempo suficiente para se difundir para a austenita que é formada em pequena quantidade. Com isso, a ferrita fica supersaturada de nitrogênio, fazendo com que ocorra a precipitação de nitretos de cromo nos grãos de ferrita ou em seus contornos de grão [4].

Pode ser observada durante a solidificação da zona fundida (ZF), a fase austenita com três morfologias: alotriomórfica, Widmanstätten e intragranular. A austenita alotriomórfica, precipita-se em elevadas temperaturas, nucleia heterogeneamente nos contornos de grão da fase ferrita durante o resfriamento. Após a formação da austenita alotriomórfica, a morfologia da austenita de Widmanstätten nucleia nos contornos de grão da ferrita ou da austenita alotriomórfica já existente e desenvolve ao longo de planos específicos da matriz como placas paralelas. Os elementos de liga estabilizadores da austenita no aço inoxidável duplex são o níquel, o manganês e o nitrogênio. O níquel e o nitrogênio elevam a temperatura de formação da austenita e o nitrogênio possibilita a formação das partículas Widmanstätten [6]

Segundo ZAMPROGNO [] em seu trabalho foi realizada a análise da quantidade de ferrita na zona termicamente afetada (ZTA) do AID UNS S32304 e verificou-se que quanto maior o aporte térmico menor o 
teor de ferrita na ZTA, justificado pela redução da taxa de resfriamento e, consequentemente, aumento da quantidade de austenita.

A presente pesquisa objetiva estudar a influência do aporte térmico (0,5, 1,0 e 1,5 kJ/mm) na morfologia da austenita e no balanço entre as fases ferrita e austenita

\section{MATERIAIS E MÉTODOS}

O aço inoxidável duplex SAF2205 utilizado nos ensaios foi cedido pela empresa "Aperam South America”, no formato de chapas retangulares de dimensões "290 mm x 210 mm x 4 mm”. A composição química do aço, determinada por meio de Espectrometria de Fluorescência de Raios-X, era 0,01\% C, 1,81\% Mn, 0,26\% Si, $0,02 \%$ P, 22,42\% Cr, 5,42\% Ni, 3,01\% Mo, 0,19\% Cu, 0,15\% N.

As chapas foram soldadas pelo processo de soldagem GMAW, no laboratório de soldagem da ESAB. O equipamento utilizado para a solda foi o Raltrec FW1000. As chapas de SAF2205 foram soldadas utilizando o arame sólido OK Autrod 2209 com composição química: 0,024\% C; 0,41\% Si; 1,55\% Mn; 0,028\% P; 0,001\% S; 21,79\% Cr; 8,30\% Ni; 3,09\% Mo. O gás de proteção utilizado possui em sua composição 95\% Ar, $3 \% \mathrm{CO}_{2}$ e $2 \% \mathrm{~N}_{2}$.

Durante a soldagem foi utilizada uma tensão de 28 volts e uma corrente de 200 ampéres. Considerouse a eficiência térmica igual a 80\%, conforme descrito na Norma Europeia DIN EM 1011-1:2009 [9]. O aporte térmico foi variado em $0,5 \mathrm{~kJ} / \mathrm{mm}, 1,0 \mathrm{~kJ} / \mathrm{mm}$ e $1,5 \mathrm{~kJ} / \mathrm{mm}$. Para conseguir esses valores foi alterada a velocidade de soldagem e mantida constante a tensão e a corrente, utilizando a equação abaixo [10]:

$$
E=(\eta . V . I) / 1000 v
$$

onde:

$\mathrm{E}=$ energia de soldagem em $\mathrm{KJ} / \mathrm{mm}$;

$\eta=$ eficiência térmica ou rendimento do processo;

$\mathrm{V}=$ tensão no arco, em V;

$\mathrm{I}=$ corrente de soldagem, em A;

$\mathrm{v}=$ velocidade de soldagem, em $\mathrm{mm} / \mathrm{s}$.

Na Tabela 1 são apresentados os parâmetros usados na soldagem para cada aporte térmico, para o aço inoxidável duplex SAF 2205.

Tabela 1: Parâmetros utilizados na soldagem do SAF 2205.

\begin{tabular}{l|l|l|ll|l}
\hline Chapa & $\begin{array}{l}\text { Aporte Térmico } \\
(\mathrm{kJ} / \mathrm{mm})\end{array}$ & Tensão ( \pm 5volts) & $\begin{array}{l}\text { Corrente } \\
\text { ampéres })\end{array}$ & 30 & $\begin{array}{l}\text { Velocidade de } \\
\text { soldagem }(\mathrm{cm} / \mathrm{min})\end{array}$ \\
\hline A & 0,5 & 28,0 & 200,0 & & 54,0 \\
$\mathrm{~B}$ & 1,0 & 28,0 & 200,0 & & 27,0 \\
$\mathrm{C}$ & 1,5 & 28,0 & 200.0 & & 18,0 \\
\hline
\end{tabular}

Foram soldadas três chapas, uma chapa para cada aporte térmico utilizado. Primeiramente foi realizado um cordão de solda no centro de cada chapa e posteriormente os cordões de solda foram feitos equidistante da solda já realizada e nas laterais de cada chapa. Totalizando, para cada aporte térmico, três cordões por chapa (Figura 1). 


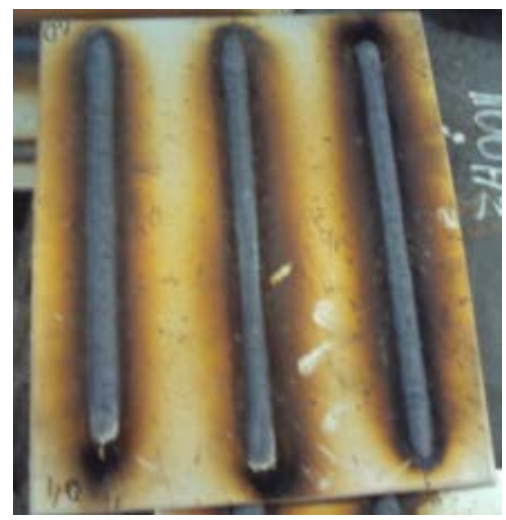

Figura 1: Chapa de aço duplex SAF 2205 soldada com aporte térmico de 1,0 kJ/mm.

O corte da chapa para análise metalográfica foi realizado na posição perpendicular ao cordão de solda, com dimensões de $25 \mathrm{~mm}$ x $50 \mathrm{~mm}$. As amostras foram embutidas a quente com baquelite, lixadas manualmente com lixas de granulometria 120, 220, 320, 400, 600 e 1000 mesh, polidas com pasta de diamante de granulometria de 9, 3 e $1 \mu \mathrm{m}$. O ataque químico foi realizado com o reativo Behara I (100 ml de água, 10g $\mathrm{NaS}_{2} \mathrm{O}_{3}$ e $3 g \mathrm{~K}_{2} \mathrm{~S}_{2} \mathrm{O}_{5}$ ) a temperatura ambiente, por 15 segundos. As análises metalográficas das fases presentes no aço foram realizadas no metal base (MB), na zona termicamente afetada (ZTA) e na zona fundida (ZF), utilizando o microscópio óptico Fortel, a fim de identificar, quantificar e avaliar a microestrutura bifásica do aço duplex 2205 e as alterações no balanceamento das fases provocadas pela variação do aporte térmico. As amostras foram analisadas e fotografadas por meio de microscopia óptica.

A análise quantitativa das frações volumétricas das fases ferrita e austenita foi realizada por meio do software Quantikov. A análise foi realizada em imagens do metal base, da zona termicamente afetada e da zona fundida, para cada uma das condições analisadas: como recebido, soldado com $0,5 \mathrm{~kJ} / \mathrm{mm}$, soldado com $1,0 \mathrm{~kJ} / \mathrm{mm}$ e soldado com 1,5 kJ/mm, atacadas com Behara 1. Para cada condição foram utilizadas 5 imagens e foi calculada a média dos resultados e os intervalos de confiança com 95\% de probabilidade de o valor real estar contido.

\section{RESULTADOS E DISCUSSÃO}

Durante o processo de soldagem foi possível verificar que quanto maior o aporte térmico maior será a molhabilidade do cordão de solda, resultando em uma maior espessura do mesmo. De acordo com MORALES [11], um maior aporte térmico resulta em maior molhabilidade do cordão de solda, uma maior penetração e menor velocidade de soldagem.

Foram observadas diferentes morfologias de austenita na região da zona termicamente afetada e da zona fundida, devido aos ciclos térmicos que o material foi submetido durante a soldagem. As morfologias de austenita precipitadas nas amostras foram: intragranular, alotriomórfica e Widmanstätten. Segundo MUTHUPANDI [7] a austenita com morfologia Widmanstätten nucleia nos contornos de grão da ferrita ou da austenita alotriomórfica pré-existente e desenvolve-se ao longo de planos específicos da matriz como placas paralelas. Já a austenita alotriomórfica de contorno de grão pode ser descontínua para velocidades elevadas de resfriamento, e à medida que a velocidade de resfriamento reduz, esta se torna cada vez mais contínua.

As Figuras 2, 3 e 4 mostram a microestrutura da ZTA e da ZF de amostras soldadas com aporte térmico de $0,5 \mathrm{~kJ} / \mathrm{mm}, 1,0 \mathrm{~kJ} / \mathrm{mm}$ e $1,5 \mathrm{~kJ} / \mathrm{mm}$, respectivamente. Pode ser verificada a presença de austenita intragranular (1), austenita alotriomórfica de contorno de grão (2) e a austenita de Widmanstätten (3). Importante salientar que em nenhuma das micrografias observadas foram encontradas fases intermetálicas que são prejudiciais ao material, como a Laves, a chi, a sigma e carbonetos,

Verifica-se nas imagens da Figura 2 a presença de austenita de Widmanstätten na ZF, morfologia não observada na ZTA. Além disso, verifica-se um aumento da morfologia de austenita intragranular na ZF (11,7 $\pm 2,1 \%)$ quando comparada à ZTA (4,9 $\pm 1,6 \%)$. Nesta última, há maior quantidade de austenita alotriomórfica de contorno de grão (19,0 \pm 1,6 \%). Segundo MUTHUPANDI [7] quanto maior a velocidade de resfriamento, maior é a tendência de precipitação de austenita alotriomórfica. Comparando a morfologia da austenita do aporte de $0,5 \mathrm{~kJ} / \mathrm{mm}$ com a dos outros aportes, verifica-se que esse aporte foi o menor utilizado, dessa forma, com maior velocidade de resfriamento, resultando em maior quantidade de austenita alotriomórfica. 


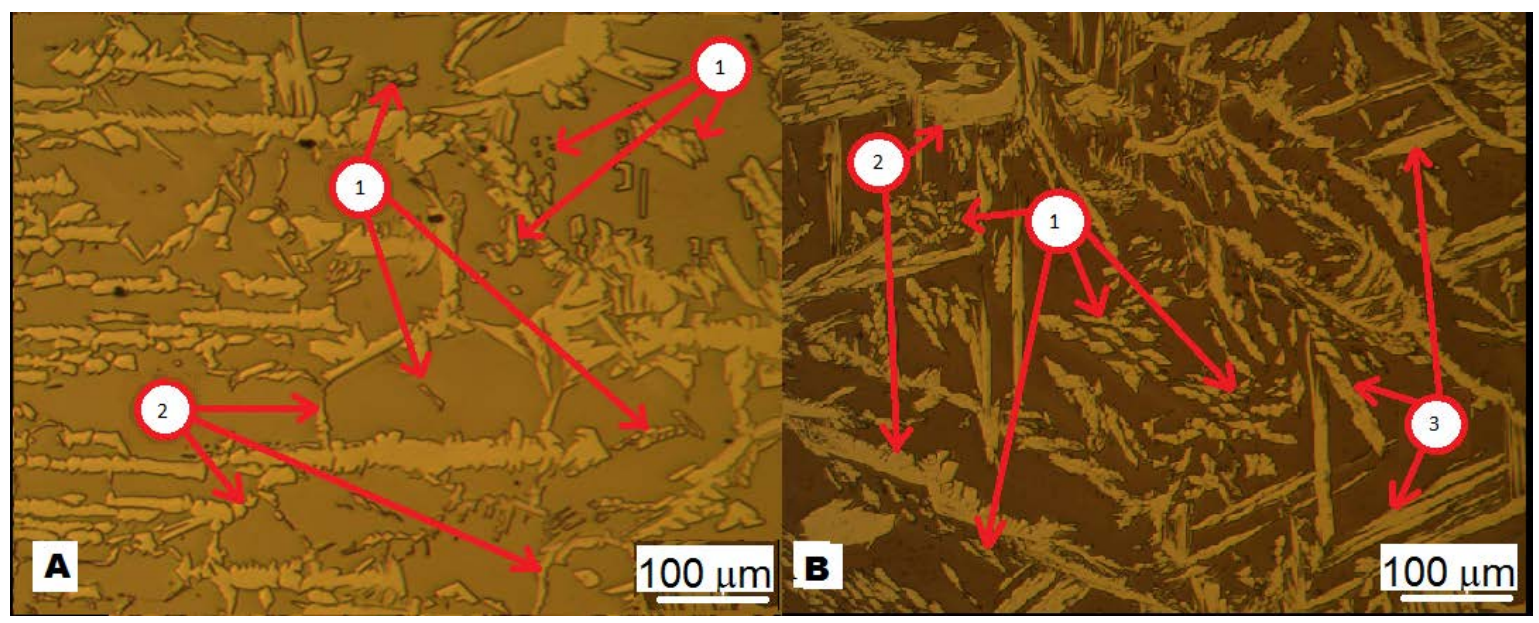

Figura 2: Diferentes morfologias da austenita, em amostras soldadas com aporte térmico de $0,5 \mathrm{~kJ} / \mathrm{mm}$ na (a) ZTA e na (b) ZF.

Nas Figuras 3(A) observa-se que a ZTA das amostras soldadas com aporte térmico de 1,0 kJ/mm é semelhante a ZTA das amostras soldadas com $0,5 \mathrm{~kJ} / \mathrm{mm}$, diferenciando o tamanho do grão de austenita alotriomórfica que é maior nas amostras soldadas com aporte térmico de 1,0 kJ/mm. Pode ser observada na Figura 3 maior quantidade de austenita de Widmanstätten na ZF (10,7 $\pm 1,2$ \%) que na ZTA (3,6 $\pm 1,9 \%$ ). A mesma observação foi verificada para a fração volumétrica de austenita intragranular que é de 9,5 $\pm 1,0 \%$ na ZTA e de 23,0 $\pm 2,1 \%$ na ZF.

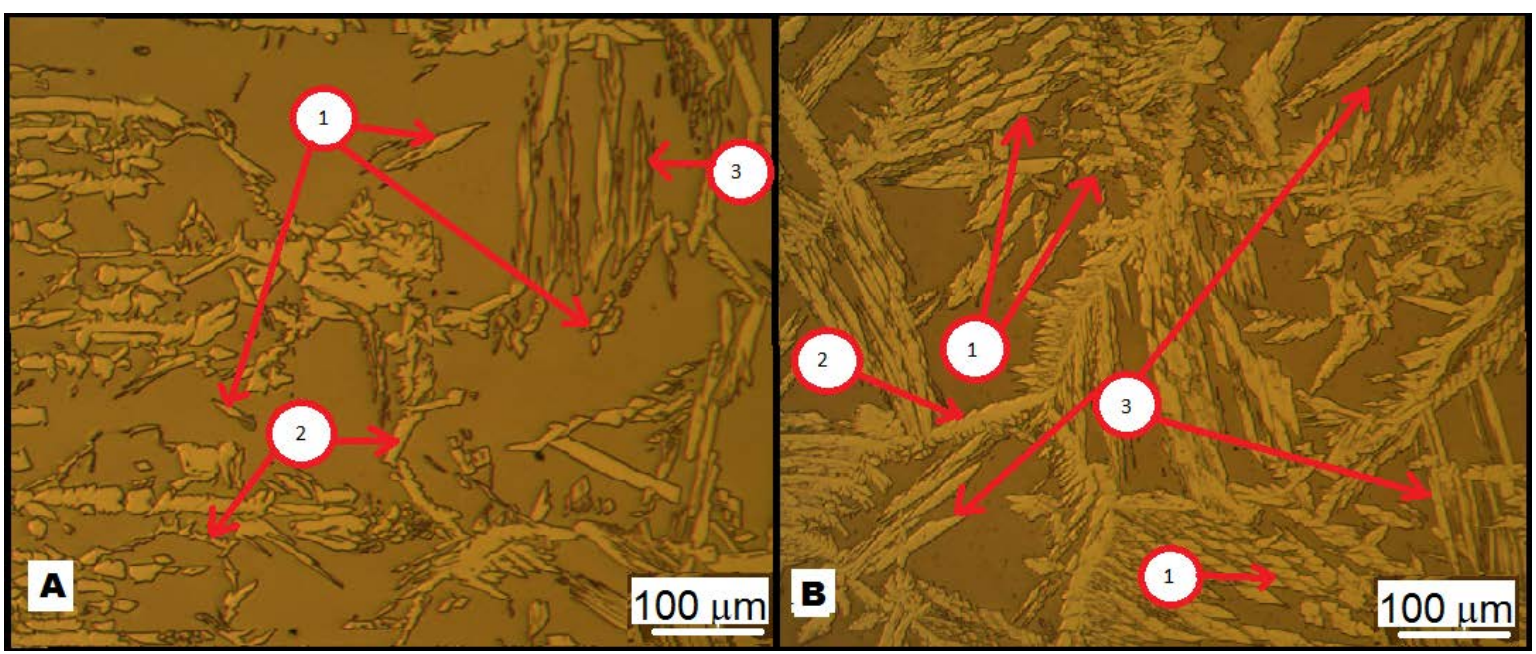

Figura 3: Diferentes morfologias da austenita, em amostras soldadas com aporte térmico de 1,0kJ/mm na (a) ZTA e na (b) ZF.

Na Figura 4 (A) observa-se a presença de austenita nas três morfologias. Na Figura 4 (B), pode ser verificada maior quantidade de austenita Widmanstätten $(14,7 \pm 2,0 \%)$ que nas amostras soldadas com 0,5 $(4,0 \pm 1,0 \%)$ e $1,0 \mathrm{~kJ} / \mathrm{mm}(10,7 \pm 1,2 \%)$. Esse fato é justificado, uma vez que quanto maior o aporte térmico, menores as taxas de resfriamento, e essas menores taxas proporcionaram maior formação de austenita do tipo de Widmanstätten [5]. Observa-se, também, aumento da austenita intragranular na ZF das amostras soldadas com aporte de $1,5 \mathrm{~kJ} / \mathrm{mm}(26,6 \pm 1,0)$. 

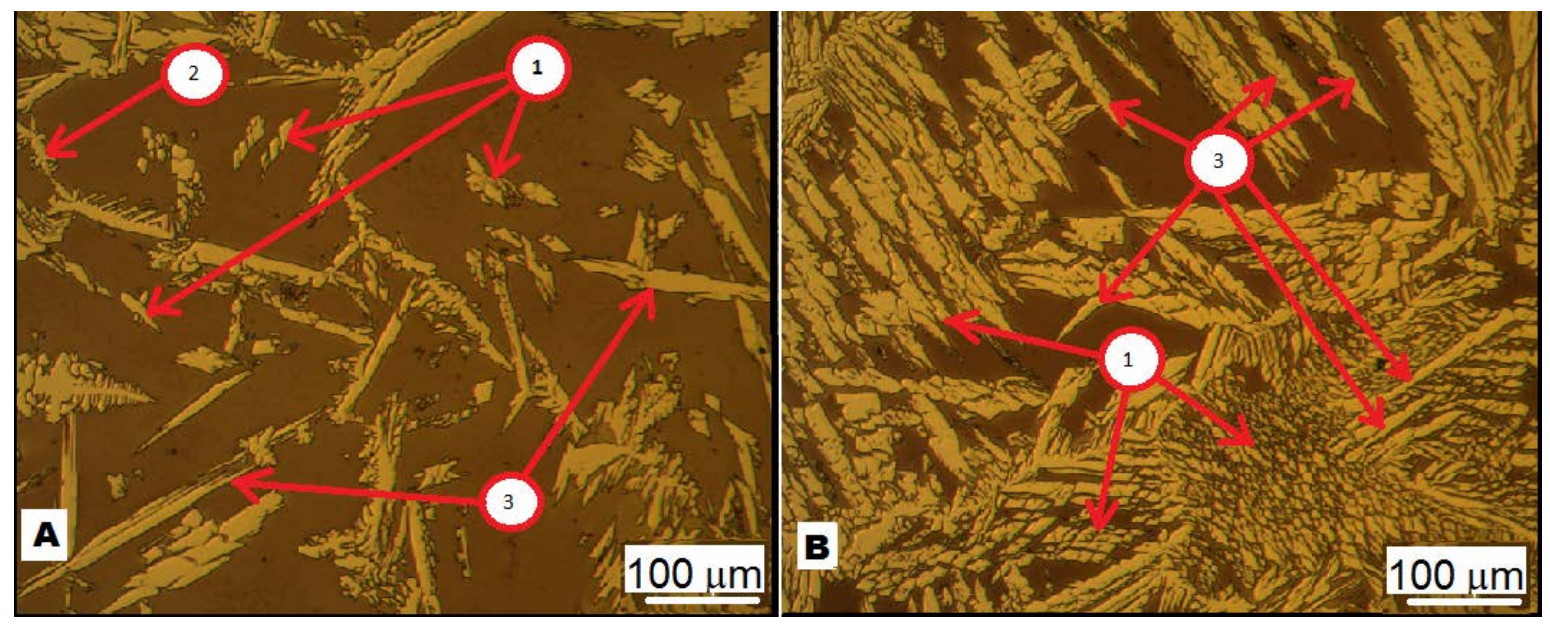

Figura 4: Diferentes morfologias da austenita, em amostras soldadas com aporte térmico de 1,5kJ/mm na (a) ZTA e na (b) ZF.

Os resultados observados para a morfologia da austenita estão de acordo com a literatura. Segundo ZAMPROGNO [8] o aporte térmico influência na quantidade e tipo de morfologia da austenita formada nas regiões de solda.

Para o cálculo das frações volumétricas de cada fase o Quantikov utiliza a diferença de cores entre elas. Por meio dos resultados das análises das frações volumétricas no MB, na ZTA e na ZF verificou-se maior percentual de ferrita na ZTA das amostras soldadas e balanço das fases no metal base. A análise quantitativa das frações volumétricas das fases ferrita e austenita presentes no SAF2205 como recebido mostrou que as proporções são relativamente iguais. Através do software Quantikov foram encontradas as seguintes médias:

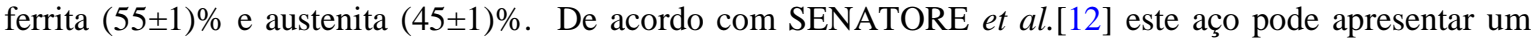
leve desvio na proporção destas duas fases cristalinas,em função do tipo de processamento utilizado.

As análises quantitativas das frações volumétricas no MB, na ZTA e na ZF, relativas às amostras soldadas com aporte térmico de $0,5 \mathrm{~kJ} / \mathrm{mm}, 1,0 \mathrm{~kJ} / \mathrm{mm}$ e $1,5 \mathrm{~kJ} / \mathrm{mm}$, podem ser visualizadas nas Tabelas 2, 3 e 4 , respectivamente.

Verifica-se na Tabela 2 que a quantidade de ferrita aumentou na ZTA quando comparado ao MB e que a quantidade de ferrita na ZF aumentou em menor percentual com relação ao MB. Segundo ROLDÃO [13], quando se utiliza na soldagem um aporte térmico menor, resulta em uma taxa de resfriamento maior, o que não possibilita tempo suficiente para formação da mesma fração volumétrica da austenita do metal base. Fato verificado na Tabela 2, na qual se observa uma redução do percentual de austenita na ZTA e na ZF.

Tabela 2: Fração de ferrita e austenita (amostra- $0,5 \mathrm{~kJ} / \mathrm{mm}$ ).

\begin{tabular}{ll|ll|l|ll}
\hline \multirow{2}{*}{$\begin{array}{l}\text { Regiões } \\
\text { da solda }\end{array}$} & \multirow{2}{*}{ Média } & \multicolumn{2}{l|}{$\begin{array}{l}\text { Intervalo de Confiança } \\
\text { Limite inferior }\end{array}$} & Limite superior & Média & \multicolumn{2}{l}{$\begin{array}{l}\text { Intervalo de Confiança } \\
\text { Limite inferior }\end{array}$} & Limite superior \\
\hline MB & 55,2 & 54,3 & 56,1 & 44,8 & 44,1 & 45,5 \\
ZTA & 76,1 & 75,2 & 77,0 & 23,9 & 23,2 & 24,6 \\
ZF & 64,4 & 62,0 & 66,8 & 35,6 & 34,2 & 37,0 \\
\hline
\end{tabular}

Na Tabela 3 observa-se que a quantidade de ferrita aumentou na ZTA quando comparado ao MB e que o percentual formado de austenita na ZF ficou mais alto que do MB. Fato justificado pela redução da taxa de resfriamento devido ao aumento do aporte térmico, resultando em tempo suficiente para a formação de austenita. 
Tabela 3: Fração de ferrita e austenita (amostra-1,0 kJ/mm).

\begin{tabular}{|c|c|c|c|c|c|c|}
\hline \multirow{3}{*}{$\begin{array}{l}\text { Regiões } \\
\text { da solda }\end{array}$} & \multicolumn{3}{|c|}{ Ferrita (\%) } & \multicolumn{3}{|c|}{ Austenita (\%) } \\
\hline & \multirow{2}{*}{ Média } & \multicolumn{2}{|c|}{ Intervalo de Confiança } & \multirow{2}{*}{ Média } & \multicolumn{2}{|c|}{ Intervalo de Confiança } \\
\hline & & Limite inferior & Limite superior & & Limite inferior & Limite superior \\
\hline MB & 55,2 & 54,3 & 56,1 & 44,8 & 44,1 & 45,5 \\
\hline ZTA & 74,0 & 71,3 & 76,7 & 26,0 & 23,3 & 27,9 \\
\hline $\mathrm{ZF}$ & 40,1 & 36,6 & 43,6 & 59,9 & 56,4 & 63,4 \\
\hline
\end{tabular}

Observa-se na Tabela 4 que a quantidade de ferrita e austenita, tanto na ZTA, quanto na ZF ficaram mais próximas do MB do que nas outras duas condições de soldagem utilizadas, ocorrendo um balanço das fases. Portanto, este valor de aporte térmico foi o que menos alterou o a proporção volumétrica entre as fases do aço duplex SAF2205.

Tabela 4: Fração de ferrita e austenita (amostra-1,5 kJ/mm).

\begin{tabular}{ll|ll|l|ll}
\hline \multirow{2}{*}{$\begin{array}{l}\text { Regiões } \\
\text { da solda }\end{array}$} & \multirow{2}{*}{ Média } & \multicolumn{2}{l|}{$\begin{array}{l}\text { Intervalo de Confiança } \\
\text { Limite inferior }\end{array}$} & Limite superior & \multirow{2}{*}{ Média } & \multicolumn{2}{l}{$\begin{array}{l}\text { Intervalo de Confiança } \\
\text { Limite inferior }\end{array}$} & Limite superior \\
\hline MB & 55,2 & 54,3 & 56,1 & 44,8 & 44,1 & 45,5 \\
ZTA & 59,3 & 56,4 & 62,2 & 40,7 & 38,4 & 43,4 \\
ZF & 54,1 & 51,4 & 56,8 & 45,9 & 43,2 & 48,6 \\
\hline
\end{tabular}

Os resultados encontrados estão de acordo com a literatura. Segundo ABREU et al. [14] durante o processo de soldagem, o aço é submetido a ciclos térmicos que podem favorecer o desbalanceamento de sua microestrutura. Ainda de acordo com esses autores há uma tendência de redução da ferrita com o aumento da energia de soldagem. Isso ocorre devido ao fato de que quando se aumenta a energia de soldagem, diminui-se a velocidade de resfriamento, e esse atraso no resfriamento é responsável pela nucleação e crescimento da austenita.

\section{CONCLUSÕES}

Os resultados encontrados nessa pesquisa permitem concluir que o aporte térmico influencia na morfologia de austenita e no balanço das fases ferrita e austenita do aço inoxidável duplex SAF2205. Não foram encontradas fases intermetálicas que são prejudiciais ao material, como a Laves, a chi, a sigma e carbonetos nas condições de soldagem utilizadas.

A análise das micrografias das amostras mostrou maiores quantidades de austenita de Widmanstätten com o aumento do aporte térmico. Foi possível concluir, também, que quanto maior o aporte térmico utilizado durante o processo de soldagem do aço inoxidável duplex SAF2205 menor é a quantidade de ferrita. Ambas as análises podem ser justificadas, uma vez que quanto maior o aporte térmico menor a velocidade de resfriamento, e isso proporciona maior tempo para a formação de austenita.

Conclui-se que a melhor condição de soldagem GMAW que mantém o balanço das fases ferrita e austenita é utilizando o aporte térmico igual a $1,5 \mathrm{~kJ} / \mathrm{mm}$ para os aços inoxidáveis duplex SAF2205, pois neste aporte o percentual das fases na ZTA e ZF fica próximo do metal base.

\section{BIBLIOGRAFIA}

[1] NILSSON, J. O., "Super duplex stainless steels”. Materials Science and Technology, v. 8, pp.685-700, Agu. 1992.

[2] SILVA, A. L. V. C., MEI, P. C., Aços e ligas especiais, 3 ed., São Paulo, Blucher, 2010.

[3] JANA, S. "Effect of heat input on HAZ properties of two duplex stainless steels", Journal of Materials Processing Technology, v. 33, pp. 247-261, 1992.

[4] PEREIRA, P.A.S. Efeito da energia de soldagem na microestrutura de um aço inoxidável duplex e super duplex.Tese de D. Sc.,Universidade Estadual do Norte Fluminense Darcy Ribeiro, Rio de Janeiro, 2009. 
[5] GNANASUNDARAM, B.R., NATARAJAN, M. "Influences of the heat input on a 2205 duplex stainless steel weld”,Materials and Technology, v.48, n.5 , pp. 761-763, 2014.

[6] AHN,Y.S., KANG, J.P. "Effect of aging treatments on microstructure and impact properties of tungsten substituted 2205 duplex stainless steel”. Journal of Materials Science \& Technology, v.16, pp.382-388, 2000.

[7] MUTHUPANDI, V., et al. "Effect of nickel and nitrogen addition on the microstructure and mechanical properties of power beam processed duplex stainless steel (UNS 31803) weld metals”, Materials Letters, v. 59, pp. 2305-2309, 2005.

[8] ZAMPROGNO, E.B., et al. "Influência da variação da energia de soldagem na formação da microestrutura do aço UNS S32304”, In:VI Congresso Nacional de Engenharia Mecânica,10-1289, Campina Grande, Paraíba, Brasil, 18-21 Agosto 2010.

[9] DIN EM 1011-1: welding- recommendations for welding of metallic materials. Part1: general guindance for arcwelding. Versão Alemã da EN 1011-1, 2009.

[10] MARQUES, P.V. Tecnologia de soldagem. Belo Horizonte: Fundação Cristiano Otoni - FCO. ESAB., 2002.

[11] MORALES, R.F., RESENDE, A.A.,et al.,Influência da adição de hélio no gás de proteção sobre a geometria do cordão de solda MIG/MAG de aço ao carbono. Tese de D. Sc., Universidade Federal de Uberlândia, Uberlândia, 2007.

[12] SENATORE, M., FINZETTO, L., et al.,” Estudo comparativo entre os aços inoxidáveis duplex e os inoxidáveis AISI 304L/316L”, Revista Escola de Minas,v.60,pp. 175-181, 2010.

[13] ROLDÃO, A.M.B. Estudo do efeito do aporte térmico nas propriedades mecânicas e microestruturais do Aço Inoxidável Duplex UNS S 31803 em chapa grossa, soldado pelo processo GMAW. Tese de D. Sc., Universidade Federal de Minas Gerais, Belo Horizonte,2010.

[14] ABREU, H. F. G., MENEZES, J. W. A., et al.,"Efeito da energia de soldagem sobre a fração volumétrica da fase ferrítica no aço inoxidável duplex UNS S 31803”, In: $3^{\circ}$ Congresso Brasileiro de P\&D em Petróleo e Gás, 3, Salvador, Brasil, 2-5 Outubro 2005. 